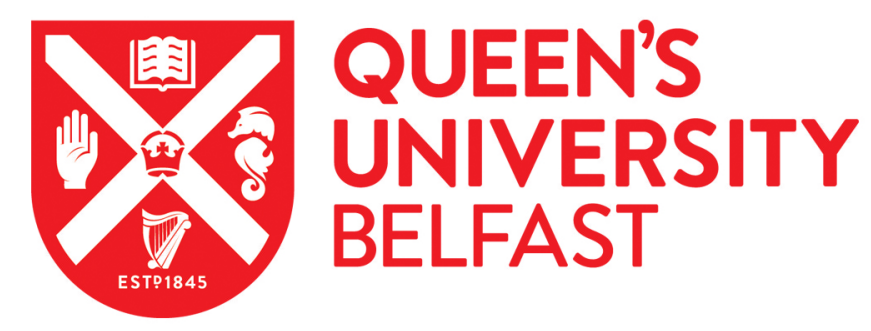

\title{
Performance without Barriers: improvising with inclusive, accessible digital musical instruments
}

Schroeder, F., \& Samuels, K. (2019). Performance without Barriers: improvising with inclusive, accessible digital musical instruments. Contemporary Music Review, 38(5), 476-490.

https://doi.org/10.1080/07494467.2019.1684061

\section{Published in:}

Contemporary Music Review

\section{Document Version:}

Peer reviewed version

Queen's University Belfast - Research Portal:

Link to publication record in Queen's University Belfast Research Portal

Publisher rights

(c) 2019 Informa UK Limited, trading as Taylor \& Francis.

This work is made available online in accordance with the publisher's policies. Please refer to any applicable terms of use of the publisher.

\section{General rights}

Copyright for the publications made accessible via the Queen's University Belfast Research Portal is retained by the author(s) and / or other copyright owners and it is a condition of accessing these publications that users recognise and abide by the legal requirements associated with these rights.

Take down policy

The Research Portal is Queen's institutional repository that provides access to Queen's research output. Every effort has been made to ensure that content in the Research Portal does not infringe any person's rights, or applicable UK laws. If you discover content in the Research Portal that you believe breaches copyright or violates any law, please contact openaccess@qub.ac.uk. 


\section{Performance without Barriers: improvising with accessible digital musical instruments in inclusive music making}

Koichi Samuels and Franziska Schroeder*

Performance without Barriers research group, Sonic Arts Research Centre, Queen's University Belfast

*f.schroeder@qub.ac.uk

Koichi Samuels is visiting research fellow at Sonic Arts Research Centre, a founding member of Performance without Barriers research group, and currently Programme Manager at Drake Music NI. Koichi is a music researcher and electronic musician. He completed his $\mathrm{PhD}$ research on inclusive music in a collaborative study with Drake Music NI and Sonic Arts Research Centre, Queen's University Belfast. His current research and work focus now is in music and social inclusion, creative economy and music technology.

Franziska Schroeder is the founder of the 'Performance without Barriers' research group, based at the Sonic Arts Research Centre, Belfast. Funding for ongoing work has been received by the UK's Arts and Humanities Research Council (AHRC), allowing the group to benefit from $\mathrm{PhD}$ and post-doctoral researchers and to expand work into emerging technological fields.

Franziska is a saxophonist, improviser and senior lecturer at Queen's University Belfast where she teaches digital performance, improvisation, and critical theories.

Performance without Barriers: improvisation and accessible digital musical instruments in inclusive music making 
The 'Performance without Barriers' ${ }^{1}$ research group (PwB), based at the Sonic Arts Research Centre at Queen's University Belfast has been exploring the potential of sonic arts practices and music improvisation for enhancing social inclusion. To date the group has primarily focussed on research activities related to the inclusive potential of providing access to music improvisation for people with physical disabilities via the use of digital technologies. In this paper we discuss the critical thinking behind our work which draws together the social and connective functions of music making, the open and relational practice of music improvisation and technological solutions utilising open, adaptable and accessible digital technologies. Three case studies of our work are discussed and the voices and experiences of participants in these projects are introduced. In this article we argue that activities in music improvisation have inclusive potential for opening constructive dialogues between performers, their instruments and people of different backgrounds and abilities. Furthermore, as we have approached our research activities reflexively, we reflect on the contradictions, dilemmas and points of learning we have discovered when engaging in collaborative and public engagement work between researchers working in a university context and the wider society.

Keywords: improvisation, inclusion, accessible music technology, digital musical instruments (DMI), performance, music and disability

\section{Introduction}

Ways to enable inclusive music making for people with disabilities is receiving growing attention and efforts from academic researchers, charity organisations, activists and musicians.

\footnotetext{
${ }^{1}$ www.performancewithoutbarriers.com
} 
Inclusive education is an important area of policy and pedagogical practices which have led to the formation of inclusive music education. In addition, Music Therapy and Community Music Therapy are areas which have focussed on providing musical engagement with therapeutic outcomes in response to health challenges that music therapy clients face, including people with disabilities. Music and arts organisations are also working to provide access to people with disabilities on a community level. Further, technological solutions for accessible music engagement has been researched and developed by academic and independent researchers and technologists (Anderson and Hearn 1994; Farrimond et al., 2010; Oliveros et al., 2011; Jewel and Atkin, 2013; Andersson and Cappelen, 2014; Gehlhaar et al., 2014; McCloskey, 2014; Mattosian and Gehlhaar, 2015; McHale, 2015; Frid, 2018; Samuels, 2019).

These devices, also often used in music improvisation practices, and which utilise the tools and methodologies of digital sound practices, challenge traditional ontologies of music and our understandings of what constitutes a musical instrument, a musician, and modes of music composition, improvisation and performance. Research suggests that music making with music technology can act as a medium through which individuals who may be marginalised or excluded and who face significant challenges in their lives, can acquire a new mode of self expression, foster self-determination and achieve positive social outcomes (Oliveros et al., 2011; Gehlhaar et al., 2014; McHale, 2016; Stewart et al., 2017; Samuels, 2019).

The 'Performance without Barriers'2 research group (PwB), based at the Sonic Arts Research Centre and founded by Dr Franziska Schroeder in 2015, has been exploring the potential of sonic arts practices and music improvisation for enhancing social inclusion. To date the group has primarily focussed on research activities related to providing access to music improvisation for people with physical disabilities via the use of digital technologies. In 2018,

\footnotetext{
2 www.performancewithoutbarriers.com
} 
these activities have expanded to include emerging technologies, such as virtual reality. The group's activities have primarily investigated the following research questions:

i) To what extent can creative practices with sonic arts contribute to social inclusion? ii) In what ways can music improvisation with digital musical instruments be utilised to provide access to music making for individuals with different abilities? iii) In what ways, if at all, can these practices contribute to challenging dominant assumptions or exclusive identities?

These practice-based research activities come from an active humanistic perspective of aiming to seek ways to positively contribute to social inclusion where the dignity of people of all abilities and diverse differences are respected and upheld (UN Assembly, 1948). PwB is a collaborative partnership between sonic arts and improvisation researchers based at the Sonic Arts Research Centre (SARC), Queen's University Belfast and a community partner, The Drake Music Project Northern Ireland $\left(\mathrm{DMNI}^{3}\right)$.

DMNI is a charity which works at the intersection of disability, music making and music technology. DMNI states that it exists to provides access to independent music making for children and adults with complex disabilities through the use of adapted and accessible music technology. Accessible music technology (AMT) practices at DMNI entail matching or adapting a music technology device to a user's specific need. DMNI employs trained community musicians to facilitate inclusive music workshop ${ }^{4}$ provision to day centres and community

\footnotetext{
${ }^{3}$ www.drakemusicni.com

${ }^{4}$ Workshops can be comprised of a mix of people and abilities and can also be held in Special Educational Needs and Disability (SEN/D) schools or groups that provide support for people who live with the same disabilities or challenges. In addition, DMNI provides one-to-one music tuition through composition workshops. The range of musical ability in DMNI workshops also varies between workshops and groups. Some participants have no musical experience and others are proficient instrumental musicians. Others still have music technology experience, but are not instrumental musicians. The range of workshops provided by DMNI are diverse and not uniform in size, age group, range of abilities, musical experience or community group.
} 
groups across Northern Ireland and to host inclusive ensembles at its three studios in Newry, Belfast and Derry/Londonderry.

We understand the activities of our 'Performance without Barriers' research group as complementary to the music activities that DMNI participants are already engaged in. We take a socially engaged approach to sonic arts and music improvisation with digital devices. This has come from the exploration of socially engaged sonic arts practices; applying the tools and methodologies of sonic arts and improvisation into inclusive and community music settings outside of the university and also bringing the community musicians and workshop participants from DMNI into research activities at SARC.

In this article, we discuss the conceptual thinking behind the activities of the Performance without Barriers research group. The first focus is with the social and inclusive potential of music itself. We then discuss improvisation as a social, political and aesthetic practice and its links to inclusive music practices. We a look at the potentiality of digital media for inclusive practices and then provide some project examples of the activities which PwB has engaged in, discussing findings, the challenges and some problems.

\section{Music as social practice}

In recent years, the academic turn to viewing music as a social process (Small, 1998; DeNora, 2000; Clarke, 2005, Turino, 2008) has led to a focus on the potential for music to be a medium with connective functions across individual, social, cultural and political difference (Solie, Ed., 1995; Urbain, Ed., 2008) and with uses in practices through which health and disability statuses can be challenged and understood differently (Straus, 2006; Lubet, 2009; Carlson, 2013, MacDonald, 2013; DeNora, 2015; Stewart et al., 2017). 
When considering music making practices and genres, people who have different bodies and abilities become significant when viewed from the perspectives of hierarchies of power and exclusion. Thus, it is important to ask the questions: who does the music belong to? Who is it made for? Who is excluded from it? (Solie, Ed., 1994) Musicking has the potential to translate and bridge across differences, and at the same time has the potential to reinforce social norms, or accepted ways of being, and exclude people who are different or do not fit the norm.

Music can also have the function of being a medium for challenging and pushing back on exclusionary identities, social attitudes and assumptions. Through music making and performance, performers can enact musical resistances of restrictive labelling or assumptions (Stewart, et al., 2017).

Music is a communicative medium that can link and move across people with differences. One way that music can bring people together is in sharing in a unified object and goal. Music can also have rhythmic and harmonic, as well as sonic properties that can unify performers and audiences in a shared experience in time and space. This sharing in time and space goes beyond a physical and material interaction in that music functions as a mode of communicative action (DeNora, 2015), and a means for social and creative collaboration.

Many studies suggests that music making and performance practices can lead to emergent artistic and empathic exchange through which individuals can form musical group identities and ways to relate to each other and themselves (Andsell, 2010; Stige, 2010; Bakan, 2014; DeNora, 2015).

The extra-musical benefits, well-being and social skills to be gained from group musical engagement for people of all ages and abilities have also been well documented (DeNora, 2000; Hallam, 2010; MacDonald, et al., 2012; Creech et al., 2013; Ansdell, 2016). Meaningful music 
experiences which are enjoyable and rewarding have been evidenced in supporting the intellectual, social and personal development of children (Hallam, 2010), and they have also been expressed as the foundation of inclusive music education (Jellison, 2012).

Many studies emphasise that active music making, improvisation and performance, rather than passive modes of musical experience, are particularly beneficial, leading to a sense of achievement through progression in music and creative expression (Hallam, 2010; Creech, 2013), contributing to strengthening an individual sense of self and also the creation of a musical community (Stige, 2002; Andsell, 2014).

Music performance has been researched for its beneficial individual and social effects. Music Therapy research has identified performance as affording participants the feeling of being able to give back to the community and having one's talents and creativity valued and praised (Ahessy, 2015: 149). Through the process itself, performance as well as music improvisation can promote cohesion within a group as relationships are created and sustained through musicking with others (Ansdell, 2010: 168). In addition, performances have been found to promote a sense of achievement and self-worth in the participant (Turry, 2005). Stige et al. (2010: 174-176) assert that musical performance affords an opportunity for individuals to perform beyond themselves, and explore their individual and social identities, challenge barriers and experience individual and social development as an extramusical effect because social collaboration follows on from musical collaboration (ibid). The same is true for practices of music improvisation.

From above perspectives it is evident that music making has a function for enhancing individual well-being and contributing to social cohesion and inclusion. However, it is also evident that not all music engagement will necessarily be beneficial or can be called inclusive and again, the same is true for practices of music improvisation, which, equally, can be highly 
exclusive. Thus, for our creative practices, whether these employ improvised or pre-composed methods, in order to achieve positive outcomes for all involved, we have found the community partnership with DMNI highly essential as DMNI promotes all participant's ability to participate in workshops and all participants have the opportunity to gain extra-musical benefits such as: self-confidence, a sense of achievement, social skills, the opportunity for creating friendships and meaningful social relationships (Samuels, 2018).

In the next section we turn in depth to music improvisation as a form of aesthetic, social and political organising, in particular as we see music improvisation as a great potential practice for embracing diversity and enhancing inclusion.

\section{Improvisation and Inclusion}

Since improvisatory approaches in music making tend to suggest fluid ways of being in each other's company, we use music improvisation as a framework for thinking about issues around inclusion and celebrating diversity, particularly in our PwB research. Improvisation is a social undertaking which can create a space for difference, allowing for a diversity of voices and meanings. In using an improvisation framework we particularly think about how musicians with a disability might easily be excluded, specifically when working with digital technologies. Improvisation is a co-created activity that endeavours to continuously question exclusionary identities and assumptions. Music improvisation can facilitate, as Heble (2005) suggests, "new kinds of global and intercultural conversations, [...] new models of human relationship, [and] alternative kinds of pedagogical practice" (Heble 2005: 1). Improvisational practices foster 
choice, collectivity, community-building, discovery (of self and other), dialogue, interconnection, listening, questioning (of self and other), responsibility, among many other qualities. Schroeder, in her edited volume "Soundweaving" (2014: xii), has teased out a more comprehensive list of terms which, at the time of writing, seemed to poignantly describe various positions on the theme of improvisation. Most importantly, improvisation allows the musician "the freedom to behave in accordance with [one's] response to the situations" (Evan Parker in Corbett 1994: 203). We side with Paul Stapleton who sees improvisation as allowing us an "opportunity to both challenge and further develop our personal and cultural identities" (Stapleton 2013: 7). The writings of Fischlin and Heble (2004); Nicholls (2012) and Fischlin, Heble and Lipsitz (2013) understand improvisation as collective, co-created, ethical and political; as a complex social phenomenon that "mediates transcultural inter-artistic exchanges, [producing] new conceptions of identity, community, history, and the body" (Heble and Siemerling, 2010: 4).

Music improvisation, to us, is an inclusive practice, which can generate empathic exchanges amongst a community of people, while forming new musical group identities. It requires what the phenomenologist Alfred Schutz refers to as making of communicative relatedness and a construction of a 'We', what Schutz thought of as a 'somatic interconnectedness' or "mutual tuning-in relationship" (Schutz 1971: 176-7). Improvisation is therefore a social activity, requiring what Heidegger calls 'attunement' (in German: Stimmung), referring not only to the tuning of a musical instrument ('to tune an instrument'), but also to a social condition of connecting to a mood ('to tune into someone') (1962: 172).

\section{Risk and process}


In engaging in an improvisation, the improviser must accept a certain lack of control and that implies being open to the possibility of encountering the unexpected / the unpredictable, and maybe even chancing upon the impossible. Most of all, the improviser has to be open to what is happening in each moment, and to learn not to be afraid of failure. Inevitably, something will happen, whatever it is, even if it might be entirely unimaginable. David Borgo tells us that a successful improvisation should have the feeling of an "improbable inevitability" (In Schroeder, 2014: 45). Improvisation is always a risky business!

Writer and improviser David Toop talks of the real necessity of improvisation for humans' survival. Humans have to learn to improvise in order to deal with the unexpected, to handle random, chaotic or accidental events and to deal with failures. Toop says that humans must learn to improvise, in order "to cope with the random events, failure, chaos, disaster and accident in order to survive..." (Toop, 2016: 1)

An inherent flexibility, or the above mentioned notion of a 'lack of control', in an improvisation is not understood as negative, as the improviser might indeed discover and create herself in the process. In such a dynamic act of playing and doing - akin to being in an innocent child-like state - the improviser invents without being concerned by the resulting object. This is a state of being and of letting things emerge without imposing one's anxieties of how or what the outcome should be; this notion of being in a process has been further explored by improviser John Stevens who saw such process as creating "a semi-unconscious stream of musical information" (Stevens et al. 1985: 59-60).

Richard Scott, likewise, emphasises improvisation not as "something "I" do but as a process, "an act of dissolving the boundaries of selfhood" (In Schroeder, 2014: 104 ). 
Keith Sawyer speaks of the idea of emergent processes and of doing things 'in-the-moment'. Rather than focusing on clearly envisaged and consciously intended musical outcomes, improvisation becomes linked to real-time creative decision- making, risk-taking and collaboration. In music improvisation there tends to be an emphasis on the process of creation as opposed to an end product alongside notions of 'collaborative emergence'. Sawyer points to the difference between process and product in creative work, stating that long periods of creative work often end in a creative product, whereas, "in improvisational performance, the creative process is the product" (Sawyer, 2000: 149). In 1995 Sawyer introduced the notion of 'collaborative emergence' in improvisational practices, arguing that the framework during an improvisational context emerges from the activity of creative collaboration of all participants, which allows complex and differentiated structures of higher levels to emerge from the organisation and interaction of simpler low-level components (1995).

\section{Music as relational and uncertain}

Music improvisation is relational. It is the result of an encounter with another: with another person, another culture, another's experiences or with other materials, but also with something 'other' than oneself, and this might be a person with different abilities, for example. Improvisation is always emergent, and thus can also introduces a state of uncertainty: “improvisation is inhabiting uncertainty together", as Parkinson, leaning on Massumi and Zournazi (2002: 214), had said. (In Schroeder, 2014: 70 ).

Improvisation is clearly not only linked to music making; it has been theorised as an activity that reaches back to the beginnings of our existence as human beings more generally. 
Keith Rowe, one of the founding members of the influential British free improvisation group AMM (initiated in London in 1965) states that improvisation, in particular free improvisation, must have been part of our culture for a long time 5 .

Writers, including Stephen Nachmanovitch in his work "Free Play: Improvisations in Life and Art" (1990), also speak of improvisation as running deeper than music and art. Nachmanovitch understands improvisation as the essence of our being; as the essence of all our natural, spontaneous interactions, something we are born with and then endeavour to recapture throughout our lives. To him, improvising is a basic life function.

Tom Nunn (1998), taking his cue from drummer Gino Robair, had also posited improvisation as a type of human play, characterised by surprise and the unknown, something that invites us to create "a response-to-the-moment excitement" (1998: 24).

Inclusive music making and the ethos inherent in free improvisation are about shared practices, and the British saxophonist Evan Parker speaks of free improvisation, particularly in its origin, as an inclusive and social, but also as a political and an aesthetic endeavour. According to Parker, free improvisation is a practice that enables musicians not only to explore their instruments in unusual ways, but allows for modes of social organisation, challenging hierarchical structures of traditional Western music and structures of political systems. In its origin, the practice of free improvisation, so Parker, was very much rooted in a kind of social egalitarianism, where musicians engaged with each other based on equality and trust.

The introduction to Heble and Caines' excellent collection of writings (2015) also states an inclusive message loud and clearly. They emphasise improvisation as more than music; as "a

\footnotetext{
5 "You can imagine lute players in the 1500 s getting drunk and doing improvisations for people in front of a log fire. The noise, the clatter must have been enormous. You read absolutely incredible descriptions of that. I cannot believe that musicians back then didn't float off into free playing" (IRowe In: Warburton, 2001).
} 
vital life-force and performance practice that has animated and activated diverse energies of inspiration, critique, and invention" (2015: 2). According to them it is an "artistic practice that accents and embodies real-time creative decision-making, risk-taking, trust, surprise, and collaboration"; a practice that teaches us about listening, responsibility and hope, "about how we can adapt to change, about how we might $[\ldots]$ choose to create a shared future" $(2015: 3)$.

Our 'Performance without Barriers' research group grounds itself in these perspectives and understandings of music improvisation, and the individual and social benefits that can be gained from engaging in music improvisation for individuals with diverse and exceptional abilities. Furthermore, we are exploring the deeper social and political significance of practices of music improvisation, which conceptually and performatively challenge individual assumptions and perceptions and social hierarchies and structures. Our group's research clearly delineates its work from music therapy, as our emphasis is on the creative involvement of each musician, celebrating divergence while challenging cultural norms; and we do not specifically aim to achieve therapeutic outcomes through music.

In the next section we detail some of the work carried out in our PwB research group.

\section{Performance without Barriers: projects}

\section{'Designing Inclusive Interactions'}

The first project by PwB took place in March 2015 as a 3-day design and music improvisation event. The event brought together student interaction designers and music technologist with Drake Music NI (DMNI) musicians and facilitators to collaboratively co-design customised accessible digital musical instruments (DMIs). The musicians had been participating in DMNI workshops from between a few months to decades and had a wide spectrum of physical and 
learning disabilities. The participating designers came from a range of backgrounds including traditional music, music technology, sonic arts, computing, and engineering. Because of the diverse set of participants, the following objectives for the workshop were decided: 1 . DMNI musicians would inform and collaborate in the design process. 2. Designers would be trained on programming sensor interfaces for music. 3. Designers would receive a theoretical and practical introduction to inclusive music making with music technology. The main outcome was an improvised music concert for a public audience, utilising the bespoke instruments in a concert hosted in the unique Sonic Laboratory ${ }^{6}$ at SARC.

The design process was user-centred and collaborative, with an improvisational attitude embedded within it. The format was a 'hackathon' style and at the start, the student designer teams interviewed the DMNI musicians to find out their physical needs for an interface, as well as their musical preferences and expectations for the project. Together and through discussion they decided the outline for the interface designs, which each team achieved by the end of Day 1. Day 2 was the major prototyping day, this time without the DMNI musicians. The four design groups built as much of the prototype interfaces as they could in the time constraints given. While the musician's needs were at the fore of the project, as Day 2 progressed the previous experience and technical skills of the student interaction designers, the constraint of time limitation, and the lack of availability of desired hardware components had a considerable impact on interface designs. In each group, resources and technical capabilities, as well as conflicts between the designer's plans and the musician's requests all acted as constraints or contradictory factors that influenced the design process. Although two out of the four groups struggled with the constraints of time and technology, all groups prevailed in formalising prototype interfaces.

\footnotetext{
${ }^{6}$ http://www.sarc.qub.ac.uk/home/sarc/facilities
} 
On Day 3 after several hours of final technical problem solving, followed by rehearsals of the improvisatory pieces, all four teams performed two improvised pieces to a public audience. The reception of the prototypes by the musicians was mixed, since for some the device had been far simpler than first discussed, falling below expectations. For other groups the device had far exceeded expectations and the DMNI musicians were impressed and happy with the results. However, all devices were working and after a period of demonstrations and testing, all DMNI musicians were able to successfully produce music gesturally in real time with the interfaces.

Through focus group discussions, participants and audience members interviews, an ethnographer documented the overall working processes. It is beyond the scope of this paper to detail the ethnographic findings and a project report ${ }^{7}$ and the music performance recordings ${ }^{8}$ can be found online.

Several of the DMNI musicians felt that they had been able to achieve a level of musical control with the customised designs that was not previously possible with the conventional, consumer music technology used at DMNI. Student designers reported that they had been able to apply their skills and expertise in a way they had never considered previously and that meeting and working with people with disabilities was a novel experience for them. Several audience members expressed that the musical expression and musicianship was different from what they were used to but not less engaging or valid. One audience member in particular related:

“... an atmosphere of collaboration and energy and a sense of people having fun. I got a sense that people were invested in the performance and that people were getting

\footnotetext{
7 https://www.dropbox.com/s/zgpvk8h05z2ziol/BigEars2015Evaluation.pdf?dl=0

${ }^{8} \mathrm{https}$ //soundcloud.com/drake-music-project-ni/sets/big-ears-drake-music-ni-performance-27th-march
} 
something worthwhile from it both the participants and the audience." (Audience member, Belfast, March 27th 2015).

Michelle McCormack, DMNI CEO responded after the event:

"The instrument ...that was designed in her group, she had a chord under each finger, and she had the ability to modulate the sound, and there's so much more that could be built into that for her. It gave her such an absolute boost of confidence, and [Participant] just turned around before she left and said, "now Michelle" she said, "I'll have to phone and talk to my piano teacher, and I'll have to tell my piano teacher she's wrong, because I can play music". (Michelle McCormack, Belfast, April 1st 2015).

Michelle had explained that this participant was initially concerned and unconfident whether she should join the event as a participant. Michelle had strongly desired to include this person and encouraged her accordingly, saying that seeing her perform was 'one of the most precious moments' for her from the event. Through the event this participant alongside all of the other DMNI musicians reported that they gained confidence, a sense of achievement, and the experience of collaboration and being part of an inclusive ensemble comprised of disabled and non-disabled peers.

The technological making practices were conceived as open and participatory, as they included the users into the design process from the very start. The designers had to respond to time and resources constraints through improvisations in the design and making of devices. Two elements of accessible DMI interface designs were: openness, and creative, improvisatory 
responses to constraints. The design process was also intrinsically linked to the music making which was completely open to the participants to improvise freely, aside from some predetermined musical decisions which guided the overall improvisatory framework. Thus, the tools created in the 3-day event with an improvisatory thinking approach, translated well to the ensemble and their use of music improvisation for the showcase performance.

\section{'Performance without Barriers'}

In 2016 PwB held a follow-up project utilising the findings and feedback from the previous year. All of the student designer teams in 2015 had faced design challenges due to the short time-scale of the project. In June 2016, PwB initiated the new project, which started with a 3-day incubator, and was planned to continue over a 6-months period.

In June 2016 six designers met with four pupils from two special educational needs schools in Belfast, Fleming Fulton and Mitchell House schools, plus one young person from the Brain Injury Matters charity. The aim was to collaborate and design a customised accessible digital musical instrument. The designers spent a further two days working on their customised interface prototypes, which were documented and taken into the schools to present to the pupils to gather feedback and design input.

After the first 3-day incubator event, designers extended time to continue designing the instruments and were given several opportunities to gather feedback from the DMNI musicians in order to integrate into the designs opinions and user experience feedback. In September 2016, the pupils and designers came together once again to finalise the prototypes and to practise performing music with them; further rehearsals continued into October. A final workshop took 
place at SARC on Sunday 27th November and concluded with a showcase performance in collaboration with the DMNI musicians at the Sonorities Festival of Contemporary Music ${ }^{9}$.

In the final performance itself the group performed two improvised pieces together as an inclusive ensemble. Following the performance, the audience was invited to come to the stage and view the instruments and to speak to the designers and performers. Detailed ethnographic reports can be found here ${ }^{10}$, and we will simply give an overall flavour of some of the participant feedback here:

Some audience members related how their eyes had been opened to what is possible in terms of inclusive music making and accessible DMI design. In this way, through the performance the instrument designers and the disabled musicians from DMNI gained access to participation and the opportunity to perform together, while contributing to the wider issue of raising public awareness for inclusive music making and disability arts. Some designers responded that they had appreciated the longer period of the project as it allowed them to create a robust and selfcontained device, whilst others felt that the gap of a several months from initially meeting the performers to the final performance day several months later, was too long and led to a loss in momentum. Another designer responded that the time constraint was positive for him as the pressure aided his process of planning and creation.

One designer told us that the opportunity had expanded his vision of what kind of projects he could apply his skills and expertise to.

“I've gotten loads out of it. It's something I've never considered before: making instruments for people with with disabilities. You're just so used to the typical controllers

\footnotetext{
${ }^{9}$ https://www.youtube.com/watch?v=9crUZ-xDf6Y\&t=19s

${ }^{10}$ https://www.qub.ac.uk/schools/media/Media,737471,en.pdf
} 
like keyboards so it was a massive opportunity to take a new perspective on how to create an interface. ..” (Ben Holmes, Sunday 27th November 2016, SARC)

Another designer also shared the positive benefits he personally gained from engaging in the project:

\footnotetext{
"Well I really enjoy building stuff like that. It's something I do as a hobby anyway and it's just a sort of fun project. Last year, especially, to see how the musicians enjoyed working with the instruments. It's really fulfilling to see how it actually does make a difference.” (Ronan Killough, Sunday 27th November 2016, SARC)
}

One other designer also found that he had to develop skills in communication for this project to be able to apply and transmit his expertise:

"Yeah, obviously, working on my own I know what all the things do and I don't have to explain it to anybody. But it's different when you're building an instrument for someone and you have to listen to what they want and it has to be easy to explain to them. It can't be too complex on the user side. So that's something I had to learn." (Conor Teahan, Sunday 27th November 2016, SARC)

In an interview a DMNI musician's mother conveyed how the music making benefitted her child in terms of both her physical body and movement, for self-expression and for creativity. 
Meabh's Mother: Do you see the way you're non-verbal and when someone gives you the chance to have a voice? Does it help with how you feel in your body?

Meabh: Yes.

Meabh's Mother: Do you find that when you use music like this that you're able to express yourself?

Meabh: Yes.

Meabh's Mother: Well you see, there's nothing for our children they can't just go to a violin lesson or something so all of a sudden the doors are all closed. Then you have this group called DRAKE coming in saying "We're doing music without boundaries” and nobody ever says that to us. Everything with our young people is about boundaries and nobody has ever approached our children and said: "How are you? What are you going to do? How will we create music with that?". It's amazing. (Meabh's mother, Sunday $27^{\text {th }}$ November 2016, SARC)

Meabh's father emphasises how the project helped him challenge his own expectations of his daughter's capabilities. Further, he related how he was impressed with the designers' engagement, attitude and behaviour throughout the event in relation to some of the performer's disabilities.

“Well put it this way, they're not afraid of her and a lot of people are afraid of approaching children with disability. they've obviously done their research and they'd done their one or two meetings and they weren't afraid and that's a big thing...Yeah, well 
you're gonna engage with it and you're open to possibilities. But we see a lot of times, people are afraid of disabilities and sometimes even family members don't know how to engage, so they just don't engage."

(Meabh's father, Sunday $27^{\text {th }}$ November 2016, SARC)

Audience members were either families and carers of the performers or musicians acclimatised to performances utilising music technology and computers. One audience member noted the intelligibility of the improvisation happening in the performance - how they could distinguish between the devices being performed with in the performance. Two other audience members noted how they could discern in what ways the designers had customised their devices to the performer's abilities:

"It was very interesting to see how they reacted. To see how the audience react to what they are seeing and hearing. We are all trying to get some different interface to play, and we all have different skills and abilities. It's interesting to see how the designers developed the interface and it was very interesting to see their reaction. They were always smiling and reacting. It was about communication, like in the other ensembles we play in."

(Suzie, Sunday $27^{\text {th }}$ November 2016, SARC)

A general feeling that audience members expressed in the feedback was that the event had brought a different feeling of joy, creative expression and togetherness, which was perceived as 
refreshing and grounding at a contemporary music festival, usually featuring avant-garde electronic music and sonic arts.

The projects in 2015 and 2016 both led to the creation of accessible DMIs with a high level of customisation for a specific disabled user, which provided access to inclusive music making in an ensemble performing improvised music. One point of reflection is that after the project, due to the facilitators and staff of DMNI's lack of specialist expertise, the accessible devices were never used again. These devices were in fact not as 'open' as they were initially designed to be (Samuels, 2015), excluding non-specialist facilitators from operating and maintaining them (Samuels, 2018). Nevertheless, these events enabled active music making, improvisation and performances that lead to a sense of achievement and creative expression for those involved. Both events highlighted the value of these events to strengthening an individual sense of self and also a sense of inclusivity and community (Stige, 2002; Andsell, 2014). Furthermore, these events resulted as an example of bringing together people across barriers of disability and difference to perform improvised music together and the potential use of open and customisable technology.

Because music improvisation is an open form of musicking, which allows for exploring different modes of social organisation and structures of traditional forms, it allowed for an inclusive mode of music creation in these events.

\section{'Immersive Inclusive Technology'}

In 2017 our PwB group received an AHRC/EPSRC award, which enabled us to expand our research into DMIs to investigate how emerging technologies such as VR (virtual reality) could be explored by disabled musicians in meaningful ways. 
Much of current VR technology is designed for able bodies; but more so, they often allow for passive interactions only. However, in PwB we are interested in how disabled musicians can use VR technologies in an active and performative way. In 2018, together with disabled musicians from Drake Music NI, we teamed up with US software developer Zach Kinstner, who had started to design a musical instrument in VR called EXA: Infinite Instrument, a musical VR instrument which runs on HTC VIVE ${ }^{11}$. The EXA instrument was developed with able-bodied musicians in mind, and our team designed this instrument to take into account different types of mobilities. This led to one of our musicians with cerebral palsy to play a new VR instrument ${ }^{12}$ that was specifically designed with her expressive great upper body movements in mind. This VR instrument did not require her to use fine motor precision in her arms/fingers, which she does not have. VR headsets are necessarily a visual interface; however, what we found is that the tactile feedback from the VIVE controllers ${ }^{13}$ allowed the musician to play the instrument by feeling and hearing it, rather than seeing the instrument through the headset. For this musician it was important not to have to rely on the use of the headset, as it allowed her visual contact with other musicians during the concert performance.

Another example of building a VR instrument from the perspective of a disabled musician was the work we developed together with a blind performer. Important to this musician was his already virtuosic skills on a clarinet. The decision thus was to build on his expertise and to adapt and enhance his musical performance skills using VR technologies. VR experiences are still very much visually guided, often disregarding the inherently immersive nature of sound (sound in its very nature is already all around us). Evidently, a visual interface such as the HTC

\footnotetext{
11 https://www.vive.com

$12 \mathrm{http}: / /$ performancewithoutbarriers.com/VRinstrument

13 https://www.vive.com/uk/accessory/controller
} 
VIVE was not meaningful to this blind musician. Therefore, our focus was on how we might use other immersive qualities of a performance space for a music performance.

As our team sits within an already immersive sound space, The Sonic LAB ${ }^{14}$, we decided to use the VIVE technology to adapt to this existing context. The Sonic LAB is a fully customisable 3D sound space, often referred to as the iMAX for the ears. For our clarinettist we focused on the VIVE controllers, as they are more tactile than visual. We used the controller's tracking possibilities for the clarinettist to position sounds in the 3D Sonic LAB.

These bespoke VR instruments featured in a showcase concert at the Sonic Arts Research Centre at Queen's University Belfast in November 2018, where disabled musicians performed alongside musicians from Belfast based professional chamber music group, the 'Hard Rain Soloist Ensemble' ${ }^{15}$. The audience was positioned in a circle closely surrounding the musicians in order to enhance the immersive experience of the performance space.

From our ongoing experience in the PwB group, and from working with disabled musicians we know that all technologies, including VR, can be inclusive if the perspective of disabled people is driving their design. In our 2018 project our inclusive approach to design exposed how new technologies could be developed, while demonstrating a commitment to the quality of life of disabled musicians. Through our research and collaborative working methods, which are deeply stepped in an improvisatory thinking framework, we also explored how VR technology can be used to actively engage disabled musicians in music making (based on Schroeder, Meireles, 2019).

\section{Conclusion - Thinking critically about PwB work}

\footnotetext{
$14 \mathrm{http}: / / \mathrm{www}$. sarc.qub.ac.uk/home/sarc/facilities/soniclab

$15 \mathrm{https}: / / \mathrm{www}$.hardrainensemble.com
} 
The research activities of PwB started from the collaborative partnership of a music technology and disability charity (DMNI) and a team of researchers working in digitally mediated or music technology based improvisation and sonic arts work (based at SARC). Both parties held two major shared understanding: i) the inclusive and socially beneficial potential of music, improvisation and performance; and ii) the openness and accessibility and thus affordances for inclusive music practices of digital music technology. DMNI comes from a hands-on approach at community and workshop level and the SARC team is equipped with both a theoretical and technical grounding in music and improvisation research; thus we have a fruitful meeting place for hands-on music practice and digital technology design.

In this paper we have outlined our theoretical considerations, drawing on our expertise in music improvisation, and our practice based design work in inclusive music making with digital tools. The projects $\mathrm{PwB}$ has been engaging with discussed here can be understood as somewhat experimental in that they have focused towards the development of prototype devices and music improvisation models, utilising techniques and tools that require specialist knowledge to operate.

We have found that DMNI musicians and facilitators, although intentionally present and participating at every stage of the process, often remain excluded from certain understandings of what and how music improvisation is being facilitated by certain devices or systems in our research activities. Thus, when PwB projects have ended, participants are not able to engage in music making with those bespoke designed instruments. PwB is working to make future research activities lead to sustainable outcomes for DMNI and the musicians, and one of our current $\mathrm{PhD}$ students is starting to develop low cost, sustainable interfaces in collaboration with DMNI musicians. 
Sustainability of accessible digital music instruments is about their access of functionality, maintenance and their translation into DMNI's actual community level workshop activities. At the same time, sustainability in our work also means enabling DMNI musicians to achieve musical progression with their devices, acquire enhanced skill and techniques over time. We are currently implementing more functional independence in using a DMI (e.g. by creating a stand alone device that does not require an assistant to aid operation) and to build into the design the potential for a user to gain mastery of playing the instruments. Both of these are indeed challenging aims, with strategies and approaches already being explored in related research (Pardue, McPherson \& Overholt, 2018) and worthy of future in-depth investigation.

In a bid to include DMNI musicians longer term in the development and direction of PwB research we are also considering how our research might lend support to the carers, facilitators and other community groups in designing and constructing their own DMIs, which may allow the DMNI musicians to feel a greater sense of ownership over their instruments and draws on thinking that instrument design is a fulfilling mode of creative expression in itself (Goldman, 2011).

In light of the above reflections, to what extent is music improvisation in PwB inclusive? If we define inclusive music as meaningful music experiences in which people with disabilities and their "typical" peers engage on an equal level in socially valued roles (Jellison, 2012: 67), the work of PwB might fall more under providing access through technological innovations and structuring situations in which people with disabilities can participate in new forms of music making and improvisation. At the same time, it is worth emphasising that through enabling participation, our work has raised awareness for the work of DMNI and inclusive music activities in Northern Ireland in areas that they had previously not achieved visibility. 
Moreover, the benefits of 'inclusion' is not a one-way street. The designers, the audiences and the researchers involved in the projects also gain from the experience, with disabled musicians teaching us new ways in which we might apply our expertise, skills, while enabling us to understand a section of society that, as musicians and academics, we may not have collaborated with. Working so closely with DMNI has opened the doors of SARC to the local community and led to other individuals and organisations collaborating with SARC and our research community and our research practices. Perhaps most importantly, our collaboration with DMNI and their musicians has allowed us to deepen our own understandings of improvisation as a potential for open and inclusive dialogue between performers, their instruments and people with different backgrounds, skills and abilities.

\section{References}

Ahessy, B. (2015). Creating community through song: A music therapy choir for older adults. In S. L. Brooke \& C. Edwin Myers (Eds.), The use of the creative therapies in treating depression (pp. 141-163). Springfield, IL: Charles C Thomas Pub LTD. 
Anderson, T., \& Hearn, D. (1994). Using hyperinstruments for the redistribution of the performance control interface. In Proceedings of the international computer music conference (pp. 183-183). San Francisco, CA: International Computer Music Association.

Andersson, A. P., \& Cappelen, B. (2014). Musical interaction for health improvement. In K. Collins, B. Kapralos, \& H. Tessler (Eds.), Oxford handbook of interactive audio (pp. 247-262). Oxford: Oxford University Press.

Ansdell, G. (2010). Where performing helps: Processes and affordances of performance in community music therapy. In B. Stige, G. Ansdell, \& C. Elefant (Eds.), Where music helps: Community music therapy in action and reflection (pp. 163-186). Aldershot: Gower Publishing, LTD.

Ansdell, Gary. (2016) How music helps in music therapy and everyday life. Routledge.

Assembly, UN General. (1948) "Universal declaration of human rights." UN General Assembly.

Bakan, M. B. (2014). Ethnomusicological perspectives on autism, neurodiversity, and music therapy. Voices: A World Forum for Music Therapy, 14(3). Advanced online publication. https://doi.org/10.15845/voices.v14i3.799

Carlson, L. (2013). Musical becoming: Intellectual disability and the transformative power of music. In M. Wappett \& K. Arndt (Eds.), Foundations of disability studies (pp. 83-104). Berlin: Springer.

Clarke, E. F. (2005). Ways of listening: An ecological approach to the perception of musical meaning. Oxford: Oxford University Press. 
Corbett, John. (1994). Extended Play: Sounding Off From John Cage to Dr. Funkenstein. Duke University Press.

Creech, Andrea, Susan Hallam, Hilary McQueen, and Maria Varvarigou. "The power of music in the lives of older adults." Research studies in music education 35, no. 1 (2013): 87-102.

DeNora, T. (2000). Music in everyday life. Cambridge: Cambridge University Press.

DeNora, T. (2015). Music asylums: Wellbeing through music in everyday life. Abingdon-onThames: Routledge.

Farrimond, B., Gillard, D., Bott, D., \& Lonie, D. (2011). Engagement with technology in special educational \& disabled music settings. London: Youth Music.

Fischlin, Daniel and Heble, Ajay (eds. 2004). The Other Side of Nowhere: Jazz, Improvisation, and Communities in Dialogue. Wesleyan UP.

Fischlin, Daniel, Heble, Ajay and Lipsitz, George (2013). The Fierce Urgency of Now: Improvisation, Rights and the Ethics of Co-creation. Durham: Duke University Press.

Frid, E. (2018). Accessible digital musical instruments: A survey of inclusive instruments. Paper presented at the International Computer Music Conference, Daegu, South Korea.

Gehlhaar, R., Rodrigues, P. M., Girão, L. M., \& Penha, R. (2014). Instruments for everyone: Designing new means of musical expression for disabled creators. In A. L. Brooks, S. Brahnam, L. C. Jain (Eds.), Technologies of inclusive well-being (pp. 167-196). Berlin: Springer.

Goldman, Andre. (2011). Materialized Music and the "monome." 
Hallam, S. (2010). The power of music: Its impact on the intellectual, social and personal development of children and young people. International Journal of Music Education, 28(3), 269-289.

Heble, Ajay (2005). Editorial: Improvising Matters: Rights, Risks, and Responsibilities. Critical Studies in Improvisation, Vol 1, No 2.

Heble, A. and Siemerling, W. (2010). Voicing the Unforeseeable: Improvisation, Social Practise, Collaborative Research. Online. Available: www.improvcommunity.ca/research/voicingunforseeable-improvisation-social-practice-collaborative-research (Accessed 13 January 2019). Heble, Ajay and Caines Rebecca (2015). The Improvisation Studies Reader: Spontaneous Acts. Abingdon: Routledge.

Heidegger, Martin (1962). Being and Time. Trans. J. Macquarrrie and E. Robinson. London: SCM Press.

Jellison, J. A. (2012). Inclusive music classrooms and programs. In B. Howe, S. Jensen-Moulton, N. W., Lerner, \& J. N. Straus (Eds.), The Oxford handbook of music education (Vol. 2, pp. 6580). Oxford: Oxford Handbooks.

Jewell, S., \& Atkin, R. (2013). Enabling technology. Royal College of Art. Retrieved from www.rca.ac.uk/research-innovation/helen-hamlyn-centre/about/resources/publications

Lubet, A. (2009). The inclusion of music/the music of inclusion. International Journal of Inclusive Education, 13(7), 727-739. 
MacDonald, R., Kreutz, G., \& Mitchell, L. (2013). What is music, health, and wellbeing and why is it important. In R. MacDonald, G. Kreutz, \& L. Mitchell (Eds.), Music, health, and wellbeing (pp. 3-11). Oxford: Oxford Scholarship Online.

Massumi, B. and Zournazi, M. (2002). Navigating Movements: AConversation with Brian Massumi. In Zournazi, M. Hope: New Philosophies for Change. New York: Routledge.

Matossian, V., \& Gehlhaar, R. (2015). Human instruments: Accessible musical instruments for people with varied physical ability. Annual Review of Cybertherapy and Telemedicine, 13, 200205.

McCloskey, J. B. (2014). inGrid: A new tactile, tangible and accessible digital musical instrument for enhanced creative independence amongst musicians with quadriplegic cerebral palsy (Unpublished Doctoral dissertation). Ulster University.

McHale, G. (2015). Sount OUT: Examining the role of accessible interactive music technologies within inclusive music ensembles in Cork city, Ireland. In D. V. Blair \& K. A. McCord (Eds.), Exceptional music pedagogy for children with exceptionalities: International perspectives. Oxford: Oxford University Press.

Oliveros, P., Miller, L., Heyen, J., Siddall, G., \& Hazard, S. (2011). A musical improvisation interface for people with severe physical disabilities. Music and Medicine, 3(3), 172-181.

Nachmanovitch, Stephen (1990). Free Play: The Power of Improvisation in Life and the Arts. Los Angeles: Jeremy P. Tarcher/Perigee. 
Nicholls, Tracey (2012). An Ethics of Improvisation: Aesthetic Possibilities for a Political Future. Lanham: Lexington Books.

Nunn, Tom (1998). Wisdom of Impulse: On the Nature of Musical Free Improvisation. Available: http://intuitivemusic.dk/iima/tn_wisdom_part1.pdf (Accessed 12 January 2019). Pardue, Laurel S., Andrew McPherson, and Dan Overholt. "Improving the Instrumental Learning Experience through Complexity Management." (2018).

Samuels, K. (2015). The meanings in making: Openness, technology and inclusive music practices for people with disabilities. Leonardo Music Journal, 25, 25-29.

Samuels, K. (2019). The Drake Music Project Northern Ireland: providing access to music making for individuals with unique abilities. Social Inclusion, vol. 7, no. 1, Cogitatio Press. Sawyer, R. Keith. (1995). Creativity as mediated action: A comparison of improvisational performance and product creativity. Mind, Culture, and Activity, 2, 172-191.

Sawyer, R. Keith (2000). Improvisation in the Arts. The Journal of Aesthetics and Art Criticism, Vol. 58, No. 2, (Spring), pp. 149-161. Blackwell Publishing on behalf of The American Society for Aesthetics. Available: www.jstor.org/stable/432094 (Accessed 13 January 2019).

Schroeder, Franziska; Meireles, Matilde (2019): How we're designing musical instruments with the help of disabled musicians and VR. In: The Conversation, 15.01.2019. Available:

https://theconversation.com/how-were-designing-musical-instruments-with-the-help-of-disabledmusicians-and-vr-109119 (Accessed 16 January 2019).

Schroeder, Franziska (Editor); Ó hAodha, Mícheál (Editor). (2014). Soundweaving: Writings on Improvisation. Cambridge: Cambridge Scholars Publishing. 
Schutz, Alfred (1971). "Making Music Together". In: Collected Papers, Vol. 2. The Hague: Nijhoff.

Small, C. (1998). Musicking: The meanings of performing and listening. Middletown, CT:

Wesleyan University Press.

Solie, Ruth A., ed. (1995). Musicology and difference: Gender and sexuality in music scholarship. Univ of California Press.

Stewart, J., Tucker, S., Williams, P. A., \& Haaheim, K. (2017). AUMI-Futurism: The Elsewhere and "Elsewhen" of (un)rolling the boulder and turning the page. American Studies Scholarly Works, 6(1), 4-24.

Stapleton, Paul. (2013). Autobiography and Invention: Towards a Critical Understanding of Identity, Dialogue and Resistance in Improvised Musics. Contemporary Music Review, Volume 32, Issue 2-03, Special Issue: Resistant Materials in Musical Creativity, pages 165-174.

Routledge.

Stevens, John; Doyle, Julia and Crooke, Ollie (1985). Search and Reflect, London: Community Music Ltd., (reprint 2007, London: Rockschool).

Stige, B., Ansdell, G., \& Elefant, C. (2010). Where music helps: Community music therapy in action and reflection. Aldershot: Gower Publishing, LTD.

Straus, J. N. (2006). Normalizing the abnormal: Disability in music and music theory. Journal of the American Musicological Society, 59(1), 113-184.

Toop, David (2016). Into the Maelstrom: Music, Improvisation and the Dream of Freedom - Before 1970. Bloomsbury Publishing Inc. 
Turino, T. (2008). Music as social life: The politics of participation. Chicago, IL: University of Chicago Press.

Turry, A. (2005). Music psychotherapy and community music therapy: Questions and considerations. Voices: A World Forum for Music Therapy, 5(1). Advanced online publication. https://doi.org/10.15845/voices.v5i1.208

Urbain, Olivier. (2008). Music and Conflict Transformation: Harmonies and Dissonances in Geopolitics. I.B. Tauris.

Warburton, Dan (2001). Keith Rowe. Paris Transatlantic Magazine. Available: www.paristransatlantic.com/magazine/interviews/rowe.html (Accessed 2 January 2019) 